\title{
HARD DETERMINISM AND THE MORAL 'OUGHT'
}

\section{LENORE KUO}

The University of Nebraska at Omaha

Philosophers from Aristotle to vanInwagen ${ }^{1}$ have questioned the possibility of preserving ethics if hard determinism is true. Thus it has been argued that we must reject hard determinism because of the apparent "violence" it does to our basic conception of morality. For example, Howard Hintz maintains that:

[Hard determinism] destroys the foundations of all prescriptive ethics except on the arbitrary-power level. If the possibility of establishing moral values and standards is removed, then the basis of meaningful and purposeful living, of human dignity, and ultimately of civilized society itself is undermined. ${ }^{2}$

In this brief paper, I shall be concerned with offering a partial answer to this charge by considering the effects of hard determinism on one of the more significant and fundamental concepts of traditional ethics, that of the moral 'ought.' By 'hard determinism' I refer to the thesis which maintains that all actions are caused and therefore no one is free with regard to his/her actions. By implication it follows that no one is morally responsible for his/her actions. In what follows, I shall demonstrate that (1) traditional assumptions regarding the moral 'ought' are, indeed, in conflict with hard

1The connection between human freedom and morality was first discussed by Aristotle in The Nicomachean Ethics (Book III, Ch. I) though philosophers gencrally cite the work of Kant in discussing the connection. Passages in The Metaphysical Principles of Virtue III, XV and in Fundamental Principles of the Metaphysics of Morals [97-98] make it evident that Kant viewed freedom as fundamental to both act and agent morality. More recently, the topic has been considered by Peter vanlnwagen, An Essay on Free Will. Oxford: Oxford University Press, 1983, pp. 207-209.

${ }^{2}$ Howard W. Hintz, "Some Further Reflections on Moral Responsibility," in Sidney Hook, Determinism and Freedom in the Age of Modern Science. New York: New York University Press, 1958, p. 163. 
determinism but that (2) the term allows for a reanalysis which, though untraditional, is coherent and meaningful. Thus although the adoption of hard determinism does confict with the traditional ethical view of the moral 'ought,' we can, by reanalysis of the term, maintain "the basis of meaningful and purposeful living, of human dignity, and ultimately of civilized society itself." 3 My argument will demonstrate that, as Sidgwick states, "the adoption of [hard] Determinism will not--except in certain exceptional circumstances or on certain theological assumptions--reasonably modify a man's view of what it is right for him to do or his reasons for doing it."4

The obvious starting point for this inquiry is to consider the question, "Is freedom implied by the moral 'ought'?" And the answer seems to be that, at least in regard to traditional morality, it is. Statements of the form, "You ought to keep promises" and "You should not have lied. You ought to have told him the truth," understood as traditional moral claims, necessarily presuppose the existence of human freedom. That they do so would seem to be undeniable if we simply recall the by now trite but nevertheless generally accepted claim that "ought implies can" (i.e., 'ought' implies that if it was the case that you ought to have done $A$, then it must be true that you could have done what you did not do).

Since hard determinism maintains that if $S$ did $A, S$ could not have done otherwise, the hard determinist cannot, without contradicting himself, make sense or use of the traditional moral 'ought.' To claim that in saying "S ought to do $A$ " one is prescribing or directing $S$ to do something which he can, in fact, do or not do--that is viewing $A$ as a real option (or choice)--is meaningless or simply false according to hard determinism. And this is no small matter. For if hard determinism is true it, at the least, changes the very nature of what we take ourselves to be saying in stating a moral rule or in making a moral judgment of an action. But, in fact, the abandonment of the traditional moral 'ought' does not necessarily destroy "the

${ }^{3}$ Although this paper is specifically intended to defend hard determinism against this criticism, it applies equally to any theory on the freedom of human action which denies that human beings are ever free (in a morally relevant sense) with regard to their actions.

${ }^{4}$ Henry Sidgwick, The Methods of Ethics. Chicago: University of Chicago Press, 1962, p. 71. 
foundations of all prescriptive ethics except on the arbitrarypower level," nor remove "the possibility of establishing moral values and standards" or undermine "the basis of civilized society itself." In what follows, I will demonstrate that although hard determinism does conflict with the meaningfulness of the moral 'ought' as traditionally interpreted it does not destroy or negate our ability to use the moral 'ought' meaningfully. In order to show this to be so, it will be necessary to offer some way of reinterpreting the 'ought' contained in moral rules and moral judgments. That is, unless we are willing to maintain that all moral rules and judgments are meaningless (a position which surely does destroy ethics), we must discover a plausible way of reanalyzing this 'ought' which does not presuppose human freedom.

For the hard determinist, the correct (or most plausible) analysis of the 'ought' of moral rules and judgments is as follows: The 'ought' in "You ought to keep your promisen is very similar, though not identical, to the 'ought' of (a) "You ought to keep a 'nest egg' (a financial emergency fund)," or (b) "You ought to try to keep a 'nest egg'." First note that in neither (a) nor (b) do we automatically presuppose that you can, in fact, keep a 'nest egg'. If this lack of presupposition is not obvious, consider the following: We would not be surprised if we turned on the P.B.S. television station during a program on personal finance and heard the lecturer state, "One ought to keep a 'nest egg'." Clearly the lecturer cannot know the details of all her viewers' finances and thus she cannot know whether or not (all) her viewers can (are financially able to) keep a 'nest egg.' Still, we do not find her statement that "one ought to keep a 'nest egg"' incoherent or inappropriate. All that is needed for the lecturer's statement to be sensible is that she assume that at least one member of the audience may someday be in a position to act on her advice. Her intent then is to define the (most) desirable action (She is stating a prima facie 'ought'--one which indicates what action would be economically desirable. And this prima facie 'ought' will become a final or an actual 'ought' i.e., one which indicates what action is in fact economically desirable, when an individual is in a position to act on it). Thus by saying, "You ought to keep a 'nest egg," she

${ }^{5}$ Hintz, p. 163. 
simply means to assert, "It would be (is) economically desirable that you keep a 'nest egg'."

As already stated, the hard determinist should construe the 'ought' of moral rules and judgments, in a way which is similar, though not identical to, the analysis of the 'ought' described above. That is, the 'ought' in "you ought to keep your promises" is the 'ought' of desirability. But what sort of desirability is here intended? While in maintaining "You ought to keep a 'nest egg"' we mean to imply "It is economically desirable to keep a 'nest egg'," when maintaining "you ought to keep your promises," we mean to imply "It is morally desirable to keep your promises." To say of something that it is morally desirable means that it is morally correct, morally right, morally good. Thus on a hard determinist analysis, by "You ought to keep your promises," we mean to imply that "It is morally desirable to keep your promises." (I.e., depending upon the circumstances we may be stating a prima facie 'ought,' one which indicates what action would be morally desirable under specific circumstances, or an actual 'ought,' one which indicates what action is morally desirable for an individual who is able to act on our statement). ${ }^{6}$

But an 'ought' of desirability does not presuppose freedom. It merely suggests behavior which is to be preferred when or if an individual is able to behave accordingly. Now it would make no sense for anyone to maintain that "S ought to do $A$ " if A were impossible (e.g. if " $A$ " were "flying out to Alaska under one's own steam"). So when one says "S ought to do $A$ " one does presuppose that $A$ is an action that it may be possible (at some time) for $S$ to perform. But one does not presuppose that $A$ is an action that $S$ will, in fact, ever be able to perform. For $S$ 's ability to perform $A$ rests on a myriad of causal conditions (including that of the influence of one's saying "S ought to do $A^{\prime \prime}$ ) which one (in all likelihood) does not know. Thus one merely suggests what action is morally desirable if $S$ is ever, in fact, in a position (if it is ever causally possible) for $S$ to do $A$.

${ }^{6}$ Since the concept of an individual being able to act on a statement may appear to imply the notion of freedom, let me briefly suggest now what should become clearer in the latter part of this discussion. When I say that "S is able to act on a statement," I simply mean that S's belief in the (content of the) statement is the only additional causal condition necessary for S's performing the action. 
But given this analysis, two related issues must be clarified:

(1) What, on this hard determinist analysis, does it mean for an action to be "morally good (right, correct)"?

(2) Given such an analysis, what are the nature and function of moral rules and moral judgments of actions? Are moral rules still prescriptive? Are they categorical or hypothetical?

The answer to question (1) is that for a hard determinist, the 'ought' of morality, the 'ought' of "You ought (morally) to do A," should be understood as "It is morally good, correct, right (i.e. desirable) that you do A." In saying this, I intend that that which is morally good (correct, right)" has the same meaning, in most cases, for the hard determinist as it does for the Libertarian or Compatibilist. That is, for example, the hard determinist Universal Hedonic Utilitarian will maintain that "A is morally good" simply means "A produces the greatest pleasure for the greatest number." The hard determinist Contractarian (i.e., one holding an ethical view which conforms to the "Social Contract" theory) will maintain that "A is morally good" simply means "A is an action which conforms to jointly acknowledged principles (principles acknowledged or agreed upon by individuals in "the state of nature"). ${ }^{7}$ Insofar as we understand Intuitionism to be the ethical view which maintains that that which is morally good is good in and of itself, the hard determinist Intuitionist will maintain that " $A$ is morally good" simply means that "A is good in and of itself (and is known to be so by intuition)."8

${ }^{7}$ This agreement either being viewed as a historical fact or as a hypothetical claim.

${ }^{8}$ Now by the above, I do not mean to imply that all conceptions of the good can be incorporated into a hard determinist account of morality. Indeed one notable exception comes immediately to mind. If one understands Intuitionism to be a view "according to which conduct is held to be right when conformed to certain precepts or principles of Duty, intuitively known to be unconditionally binding" (Sidgwick, p. 3), and if one maintains that one cannot be unconditionally bound to do that which one cannot do, then one cannot be an Intuitionist and a hard determinist.

However, the inability to incorporate such a view of 'the good' into a hard determinist analysis of morality is not a problem for hard 
We should turn, then, to question (2): What, on a hard determinist analysis of morality, are the nature and functions of moral rules and moral judgments of actions? Are moral rules still prescriptive? Are they categorical or hypothetical? I shall argue that on a hard determinist view moral rules may be viewed as prescriptive hypothetical imperatives and, further, that such a view is not altogether in conflict with traditional ethics, i.e., that within the traditional ethical literature, there are those (who are not hard determinists) who hold similar views of moral rules. Let us first consider the question of whether moral rules involve categorical or hypothetical imperatives. There is no question that the majority of ethical philosophers who view moral rules as imperatives maintain that they are categorical. But what must the determinist say in this regard? Before suggesting an answer, it will be useful to distinguish between two separate issues regarding the hypothetical or categorical nature of moral rules. One can ask "Are moral rules as rules or principles, categorical or hypothetical?" One can also ask "Are moral rules as imperatives, hypothetical or categorical?" These are distinct questions which, for the hard determinist, require different answers. ${ }^{9}$

Moral rules as rules or principles must be understood as categorical statements or claims. In claiming " $A$ is morally desirable" (or more traditionally, "One ought to do $A^{\text {"), }}$, one is claiming that A categorically satisfies formal criteria of moral rightness or goodness, and one intends to be making a straightforward truth claim (one which does not require an "if" clause to make it true). And although the formal criteria utilized to determine whether or not the claim gives a true moral principle may differ depending upon one's ethical commitments (i.e., if one is a Utilitarian, Intuitionist, Contractarian, etc.), we do not intend by " $A$ is morally desirable" that, e.g., "A is morally desirable if one is a Utilitarian." Indeed, in instances in which we find a conflict in judgments regarding the truth of a moral principle between those holding opposing ethical theories, we generally take

determinism. It would become a problem only if it could be demonstrated that all other analyses of 'the good' were false.

${ }^{9}$ l.e., unless one holds, as I suggest in footnote 10 , that one can be obligated or unconditionally bound to do that which one cannot do. 
such a conflict to indicate a disproof of the formal criteria used by at least one of the theories. Thus moral rules as rules or principles are intended as absolute or categorical statements of moral rightness, regardless of any individual's desires, philosophic commitments, etc.

But what of the question, "Are moral rules as imperatives categorical or hypothetical?" Although the term is used somewhat ambiguously in traditional ethics, by 'imperative' I mean the following: an imperative is that which expresses the intent to influence the behavior of another, whose articulation is intended to be relevant to action, it expresses a command, entreaty, advice, exhortation, etc. When considering moral rules as imperatives, we are concerned with how their expression or articulation affects behavior. And it is in this sense of 'imperative' that I wish to maintain that for hard determinists moral rules are most plausibly viewed as being or involving hypothetical imperatives. ${ }^{10}$

The view that moral rules are hypothetical imperatives has been advanced by, among others, Philippa Foot and John C. Harsanyi. ${ }^{11}$ In his article, Harsanyi (who is clearly not a hard determinist) presents and argues for an interpretation of moral rules which is nearly identical to the one I would like to suggest. ${ }^{12}$ Thus I maintain that given a hard determinist view

${ }^{10}$ One further clarification is required. Hard determinism does not necessarily require that moral rules be viewed as hypothetical imperatives. A hard determinist may view moral rules as categorical imperatives if s/he maintains the following: to say that "You ought to do $A$ " is to say " $A$ is morally desirable." " $A$ is morally desirable" is the statement of an imperative which is obligatory or unconditionally binding. One can be obligated or unconditionally bound to do that which one cannot do. I.e., if one holds that one can be obligated or unconditionally bound to do what one cannot do, then one can be a hard determinist and still maintain that moral rules are, or involve, categorical imperatives. On such a view, a hard determinist's account of the import of moral rules on actions would remain virtually unchanged.

11Philippa Foot, "Morality as a System of Hypothetical Imperatives," The Philosophical Review, 81, no. 3 July 1972): 305-16 and John C. Harsanyi, "Ethics in Terms of Hypothetical Imperatives," Mind, (1958): 305-16.

${ }^{12}$ Although I reject the relativistic overtones which Harsanyi's analysis appears to allow for if not actually favor. 
of behavior, moral rules should be viewed as hypothetical imperatives of the form "One ought to do $A$ if one desires to do that which is morally good." They provide reasons for $S$ to do A. They serve to advise or inform us (their articulation or expression affects our behavior) by telling us what sort of actions are morally good. (Thus they become one of the causal conditions of S's doing $A$ if $S$ wishes to do that which is morally good.)

Viewing moral rules as providing reasons for actions serves two purposes with regard to the concerns of this paper. First, it demonstrates that the effects of adopting a hard determinist view of behavior does not require the total abandonment of traditional ethics sometimes suggested by its critics. Secondly, the recognition that moral rules constitute reasons for actions should make it apparent that moral rules retain their significance and remain functional within a hard determinist schema. I.e., on a hard determinist account, moral rules affect actions as follows: (1) When $S$ desires "to do that which is morally good" and (2) When $S$ believes (because of a moral law which says "One ought to do A," i.e., "It is morally desirable to do $A^{\prime \prime}$ ) that if $S$ does $A$, he will be doing "that which is morally good" and (3) When other causal conditions obtain, then $\mathbf{S}$ will do $\mathrm{A}$. Thus, on a hard determinist account, moral rules (or knowledge of moral rules) conjoined with S's desire "to do that which is morally good," provide a reason for S's action. As such they are the cause, or more strictly one of the causal conditions, for S's doing A. ${ }^{13}$

The final question with regard to a hard determinist analysis of moral rules which I wish to consider here is, "Are they prescriptive?" And the answer clearly will depend upon what one takes 'prescriptive' to mean. Consider three fairly standard analyses of 'prescriptive' suggested by Morris Schlick and Haskell Fain.

In "When is a Man Responsible," Schlick offers the following analysis:

${ }^{13}$ Clearly I am here presuming the rather controversial thesis that reasons can be causes. Although it is impossible, within the confines of this paper, to offer any thoroughgoing defense of this thesis, my position on this issue is very similar to that taken by Donald Davidson in "Actions, Reasons and Causes." Review of Metaphysics, 19 (196566): 667-688. 
In practice ... ["law"] ... is understood as a rule by which the state prescribes certain behavior to its citizens. These rules often contradict the natural desires of the citizens (for if they did not do so, there would be no reason for making them), and are in fact not followed by many of them; while others obey, but under compulsion. The state does in fact compel its citizens by imposing certain sanctions (punishment) which serve to bring their desires into harmony with the prescribed laws.

In natural science, on the other hand, the word "law" means something quite different. The natural law is not a prescription as to how something should behave, but a formula, a description of how something does in fact behave. ${ }^{14}$

On such an implied analysis of 'prescription', moral laws on a hard determinist analysis are prescriptive. Even when the cause of (or a causal condition for) S's doing $A$ is a moral law, this does not preclude S's having desires which would, if the moral law was not causally efficacious in this instance, have caused $S$ to do not $A$. It is also true that on a hard determinist analysis of 'moral law,' the laws may not be followed. That is, one may be caused to act in a way contrary to the moral law. Additionally, on a hard determinist analysis, moral laws are a prescription of how one should behave and not a description of how one does, in fact, behave. Finally, as analogous to the instance of legal rules, one can be compelled on a hard determinist account by the threat of public criticism, ostracism, etc. and even by legal sanctions to follow the moral laws. That is, the threat of punishment can be a causal condition for one's decision to do A. As such, given Schlick's analysis of 'prescription,' moral laws, on a hard determinist analysis, are prescriptive.

In "Prediction and Constraint"15 Haskell Fain suggests two different interpretations of 'prediction.' The first, which Fain

${ }^{14}$ Schlick, Moritz, "When is a Man Responsible," in A Modern Introduction to Philosophy, 3rd ed. Arthur Pap and Paul Edwards (Eds). New York: Free Press, 1973, pp. 60-61. It should be noted that Schlick is not a hard determinist.

${ }^{15}$ Mind, 67, no. 267, (July, 1958): 366-378. 
does not endorse, is as follows: "It may . . . be held that the crucial distinction between prescriptive and descriptive laws consists . . . in the following: prescriptive laws may possibly be violated but descriptive laws cannot be violated. . . ." Now given such a view, moral laws on a hard determinist analysis are prescriptive. One may violate them not because one freely chooses to do so, but because one is caused to do so. Fain's second interpretation of 'prescriptive' is as follows: ". . . prescriptive laws are taken to be a subclass of a class of sentences which may be called 'commands,' and which are written or spoken with the intention of affecting human behavior. ..." And on such a view, moral laws on a hard determinist analysis still qualify as prescriptive. They can be viewed as commands which are written or spoken with the intention of affecting human behavior. They affect human behavior whenever one's knowledge of them is a causal condition for acting or, at least, attempting to act in accord with the command (one may, for example, try to be benevolent but fail due to an error of judgment). ${ }^{16}$

Although the three analyses already discussed are rather standard, I do not mean to suggest that there are no analyses of

${ }^{16}$ In "Freedom and Reason," Hare takes a view similar to that of Fain's, maintaining that prescriptions are "intended to serve as a guide to ... actions" (pp. 52-3). However in a later passage Hare holds that "...if we say that somebody ought to do a certain thing, and 'ought' has its full (i.e. universally prescriptive) force, then we give our hearers to understand that we think that the question arises to which this is a possible answer, which it would not, unless the person in question were able to do the acts referred to..." (from Freedom and Reason. Bristol: Oxford University Press, 1963, pp. 52-4)

Such a view of universal prescription might appear to conflict with the hard determinist's position. However when Hare discusses the question of free will later in the chapter (I.4.6 *4.7) it becomes apparent that he does not intend the concept of "able to do the acts referred to" in any way which would necessarily be contrary to a hard determinist's reading. Hare explicitly states that he does not intend to prejudge the free will issue and allows for the view that moral laws are prescriptive in that the individual is able to act in accord with them whenever the individual's knowledge of such laws causes the individual to act in accord with them. That is, for Hare, if moral laws guide actions by being causes or causal conditions for actions, then they are prescriptive. 
'prescription' under which moral rules on a hard determinist analysis would turn out to not be prescriptive. ${ }^{17}$ However even if this is the case, it is clear that they are not (at least purely) descriptive. Moral laws on a hard determinist analysis do not simply describe how things are but rather advise and/or inform us of what actions are morally desirable. And under the right circumstances they or our knowledge of them becomes one of the causal conditions of our actions.

In this limited space, I clearly cannot hope to answer the general charge that hard determinism is incompatible with morality. I have, however, attempted to demonstrate that it is not incompatible with a meaningful use of the moral 'ought' and thus not incompatible with having moral rules or making moral judgments of actions. It is my hope that the above discussion will make the more general charge of incompatibility suspect. For while it may be true that there are apparent problems in reconciling hard determinism with morality, these problems may not be insurmountable.

${ }^{17}$ Although I have not been able to locate any such definition in the literature, in response to an earlier draft of this paper Professor Jon Moline suggested the following analysis: To prescribe is to recommend that there are other alternatives the one receiving the prescription could, de facto, choose instead (even given the presence of the prescription). "Take this medicine twice daily and don't forget to do it on a full stomach" presupposes that the prescribee could take it once daily or nine times, and on an empty stomach or not at all. And such a suggestion appears in keeping with the intent of some discussions of moral rules as prescriptions. See, e.g. Hillel Steiner, "Moral Conflict and Prescriptivism," Mind, 82, no. 328, (October 1973).

Now clearly if this is what is intended by 'prescription' then moral laws on a hard determinist analysis are not prescriptive since one could not choose to do other than one in fact does, although the prescription itself might be a causal condition in the prescribee's deciding to do what he otherwise (i.e, without the prescription as a causal condition) would not do. 